\title{
Wave Interaction with Vertical Slotted Breakwaters
}

\author{
Karim Badr Hussein ${ }^{1}$, M.I. Ibrahim ${ }^{1}$ \\ ${ }^{1}$ Lecturer of Irrigation and Hydraulics, \\ Faculty of Engineering, Al-Azhar University, \\ Egypt
}

\begin{abstract}
This study aims to introduce two types of an innovate breakwater with an economic feasibility. The first type consists of two vertical perforated walls, the first wall is permeable in lower (porosity $\varepsilon=50 \%$ ) and the upper part is impermeable. And second wall is permeable in upper (porosity $\varepsilon=50 \%$ ) and the lower part is impermeable. between them horizontal slotted wall. the second type is the same construction as on the first type but without horizontal slotted wall. The results indicate that the hydrodynamic performance of the first type is better than that of the second type in the percentage $(10-15 \%)$ because of the presence of the horizontal slotted wall. The effect of wave force on the first model is bigger than the second model in the range (10$15 \%)$. The wave force on the proposed models increases with increasing the relative length $(\mathrm{h} / \mathrm{L})$. The transmission coefficient (kt) decreases with increasing the relative length $(\mathrm{h} / \mathrm{L})$.The reflection coefficient $(\mathrm{kr})$ increases with increasing the relative length $(h / L)$.from FLOW-3D results able to find values velocity front and behind barriers.
\end{abstract}

Key Words:- Coastal structures - Permeable breakwater - perforated wall - numerical model - refraction - transmission - energy dissipation.

\section{INTRODUCTION}

Traditional breakwaters (i.e. rubble-mound, vertical caissons and gravity wall) are widely used to provide a protected calm water area to accommodate vessels and allow loading and unloading processes. Such types possess a large width according to the water depth. Consequently, great amounts of construction material are required. Moreover; such breakwaters block the littoral drift leading to the occurrence of severe erosion or accretion. In addition, they dampen the water circulation leading to a deteriorated water quality and achieving unbalance to the ecosystem. Furthermore; traditional structures need skilled labor for their construction and certain foundation requirements. All the above leads to an uneconomic construction cost.

On the contrary, permeable breakwaters avoid the occurrence of the above side-effects, at the same time they provide reasonable protection with economic construction cost. This research was thus initiated with the objective of proposing and investigating the hydrodynamic performance of an innovative economic breakwater, numerically.

Many journals, periodicals and researches in the field of breakwaters were assembled, reviewed and comprehended from which it was clear that many researchers were occupied with finding out innovative types of economic breakwaters. Among these researchers were the following:
Wiegel (1960) and Hayashi et al. (1966) investigated breakwaters in the form of a row of close piles. Herbich (1998) investigated double rows of close piles. Suh el at. (2006); K. Laju el at. (2007) stated that breakwaters in the form of thin, rigid, pile-supported vertical barriers or many rows of piles which is placed below the water surface would provide relatively greater protection. Rageh and Koraim (2010) examined the hydraulic performance of a vertical wall with horizontal slots. The upper part was impermeable but the lower part of model was horizontal slots. Ahmed et al. (2011) investigated the hydrodynamic characteristics of a vertical slotted wall breakwater. They further stated that for more protection and more dissipation of energy a pair of permeable barriers might be desired. Isaacson et al. (1999) examined a pair of thin vertical barriers placed below the water surface. Koraim et al. (2011) and (2014) investigated the hydrodynamic characteristics of double permeable breakwater under regular waves. The model consisted of double walls with horizontal slots. Suh et al. (1995) established an analytical model for predicting wave reflection from a perforated-wall caisson breakwater. They implemented the Galerkin-Eigenfunction method to predict the reflection coefficient of a perforated wall caisson mounted on a rubble mound foundation. Hsu and Wu (1999) developed a numerical solution based on the boundary element method and boundary value problem for linear and second-order wave. Isaacson et al. (1998), Ahmed et al. (2011) and Suh el at. (2006) established the

Eigen-function expansion method for linear waves, secondorder waves and nonlinear waves. Lin et al. (2007), Huang et al. (2003), Lara et al. (2006), (2008) and Karim et al. (2009) executed numerical solutions for wave interaction with structures. They provided interesting examples for wave interaction with porous and submerged structure are reported. Ahmed (2014) investigated regular wave interaction using a numerical model of (FLOW-3D, VOF) with a single vertical perforated wall. From the reviewed literature, it was obvious that permeable breakwaters were meticulously investigated, even though; other types are required to be investigated. This research aims to propose and investigate the hydrodynamic performance of an innovative economic breakwater, numerically. The research also aims to compare the hydraulic performance for the first and the second model and the present study with the previous study.

\section{2-PROPOSING AN INNOVATIVE BREAKWATER}

The two innovative economic breakwaters were proposed, as shown in figures (1) and (2). It is a permeable breakwater that 
comprises a pair of identical vertical perforated walls. First wall is impermeable in the upper and second wall is impermeable in the lower. A porosity of a permeable part $=50 \%$. The first and second perforated walls are placed apart by a distance of 0.5 of the water depth. Model (1) is vertical perforated wall breakwater with horizontal slotted wall and model (2) is vertical perforated wall breakwater without horizontal slotted wall.

\section{3-INVESTIGATING THE PROPOSED BREAKWATER NUMERICALLY}

This section presents the implemented model and its theory. It presents the validation process of the model together with the executed numerical simulations to the proposed breakwater.

\section{1- THE IMPLEMENTED MODEL}

The proposed breakwater was investigated. This was achieved via achieving numerical simulations using the commercial "Computational Fluid Dynamics" (CFD) code FLOW-3D. This is attributed to the fact that from the assembled literature, it was clear that CFD applications are common practice in all sectors of engineering and they are increasingly becoming important in maritime and coastal engineering. Therefore, the commercial CFD code (i.e. FLOW-3D, Flow Science Inc.) was chosen to be implemented in this study.

\section{2- THEORY OF FLOW-3D}

Basically, FLOW-3D applies the finite volume theory to solve the three-dimensional Reynolds- Averaged Navier -Stokes (RANS) equations. The model consists of a group of solid subcomponents, figures (3) and (4). The numerical model within FLOW-3D represents the geometrical and hydraulic boundary conditions.

\section{3-NUMERICAL SIMULATIONS USING FLOW-3D}

Confident with the validation process, the model was implemented, varying the different parameters. Numerical replications were achieved to simulate the proposed breakwater.

In order to get a good compromise between precision/accuracy and computation time, two independent meshes with different cell sizes were used. Mesh cells are sized by $1 \mathrm{~cm}$ in each direction for waves of small frequencies and mesh cells are sized by $0.5 \mathrm{~cm}$ for waves of large frequencies. The time window for analyzing the wave height is carefully selected according to the wave length and adjusted to avoid any reflection from the flume end or the wave paddle.

The reflection coefficient was calculated by the three-probe method of Mansard and Funk (1980). The selected data are converted into frequency domain by Fast Fourier Transformation. Finally, the spectrum of the incident, transmitted and reflected wave height were calculated. Thereby, the reflection coefficient ' $\mathrm{kr}$ ' is calculated from extracted wave profiles by:

$$
k r=\frac{H r}{H i}
$$

Where: $\mathrm{Hr}$ is the reflected wave height, $\mathrm{Hi}$ is incident wave height.
The transmission coefficient ' $k t$ ' was calculated directly from the wave transmitted profile by:

$$
k t=\frac{H t}{H i}
$$

where: Ht is the transmitted wave height.

The energy dissipation coefficient ' $k \boldsymbol{d}$ ' is given $k d=1-k r^{2}-k t^{2}$

\section{4-ANYLATICAL STUDY}

The velocity potential " $\Phi$ " is assumed as periodic motion in time $T$ and it can be expressed as follows:

$\Phi(x, z, t)=\operatorname{Re} \frac{-i g h_{i}}{2 \omega} \phi(x, z) \frac{1}{\cosh k h} e^{-i \omega t}$

Where $R e$ is real part of a complex value, $\omega$ is wave angular frequency, $\mathrm{g}$ is gravitational acceleration, $i=\sqrt{-1}$ and $K$ is wave number $(\mathrm{K}=2 \pi / \mathrm{L})$.

The dispersion relationship could be formulated as: $\omega=g k \tanh (K h)$ The permeable boundary condition along the structure has been developed on the basis of the formulation of Sollit and Cross (1972) and as adopted by Yu (1995) for a thin vertical barrier. This might be given by:

$$
\begin{aligned}
& \frac{\partial \phi_{1}(x)}{\partial x}=\frac{\partial \phi_{2}(x)}{\partial x}=i G^{-}\left(\phi_{1}(x)-\phi_{2}(x)\right) \\
& \text { at } x=-a \text { for }-h \leq z \leq-D 1 \\
& \frac{\partial \phi_{2}(x)}{\partial x}=\frac{\partial \phi_{3}(x)}{\partial x}=i G^{-}\left(\phi_{2}(x)-\phi_{3}(x)\right) \\
& \text { at } x=a \text { for }-D 2 \leq z \leq 0
\end{aligned}
$$

The proportional constant $G^{-}=\frac{G}{b}, G$ is called the permeability parameter and is expressed by: $G=\frac{\mathcal{E}}{f-i \boldsymbol{S}}$

where $\varepsilon$ is the porosity of the structure given by the dimension and spacing of the piles, $f$ is the friction factor (empirical parameter) and $\boldsymbol{S}$ is the inertia coefficient and given by $s=1+c m\left(\frac{1-\varepsilon}{\varepsilon}\right)$ where $c m$ is an added mass coefficient. Eigen function expansion solved the velocity potential in a series of infinite number of solutions as follow:

$$
\begin{aligned}
& \phi_{1}(x)=\phi_{i}+\sum_{m=0}^{\infty} A_{1 m} \cos \left[\mu_{m}(h+z)\right] \exp \left(\mu_{m}(x+a)\right) \\
& \text { at } x \leq-a
\end{aligned}
$$


$\phi_{2}(x)=\sum_{m=0}^{\infty} A_{2 m} \cos \left[\mu_{m}(h+z)\right] \exp \left(-\mu_{m}(x+a)\right)+$

$\sum_{m=0}^{\infty} A_{3 m} \cos \left[\mu_{m}(h+z)\right] \exp \left(\mu_{m}(x-a)\right)$

At $\quad-a \leq x \leq a$

and

$\phi_{3}(x)=\sum_{m=0}^{\infty} A_{4 m} \cos \left[\mu_{m}(h+z)\right] \exp \left(-\mu_{m}(x-a)\right)$

At $\quad x \geq a$

Applying the matching conditions (i.e. combining (7), (8) and (9) with (4) and (5) at the breakwater; the coefficients $A_{1 m}, A_{2 m}, A_{3 m}$ and $A_{4 m}$ could be determined by the following matrix equation:

$\left[\begin{array}{llll}\sum_{m=0}^{\infty} C_{11}^{(m n)} & \sum_{m=0}^{\infty} C_{12}^{(m n)} & \sum_{m=0}^{\infty} C_{13}^{(m n)} & \sum_{m=0}^{\infty} C_{14}^{(m n)} \\ \sum_{m=0}^{\infty} C_{21}^{(m n)} & \sum_{m=0}^{\infty} C_{22}^{(m n)} & \sum_{m=0}^{\infty} C_{23}^{(m n)} & \sum_{m=0}^{\infty} C_{24}^{(m n)} \\ \sum_{m=0}^{\infty} C_{31}^{(m n)} & \sum_{m=0}^{\infty} C_{32}^{(m n)} & \sum_{m=0}^{\infty} C_{33}^{(m n)} & \sum_{m=0}^{\infty} C_{34}^{(m n)} \\ \sum_{m=0}^{\infty} C_{41}^{(m n)} & \sum_{m=0}^{\infty} C_{42}^{(m n)} & \sum_{m=0}^{\infty} C_{43}^{(m n)} & \sum_{m=0}^{\infty} C_{44}^{(m n)}\end{array}\right]\left[\begin{array}{l}A_{1 m} \\ A_{2 m} \\ A_{3 m} \\ A_{4 m}\end{array}\right]=\left[\begin{array}{l}b_{1 n} \\ b_{2 n} \\ b_{3 n} \\ b_{4 n}\end{array}\right]$

For $n=1,2,3, . . \infty$

Equation (10) could be solved by numerical tools. Consequently, $k r$ and $k t$ could be obtained;

$$
\begin{gathered}
k r=\left|A_{10}\right| \\
k t=\left|A_{40}\right|
\end{gathered}
$$

The energy dissipation coefficient can be determined using equation (3).

\section{5- HYDRODYNAMIC FORCE}

The hydrodynamic pressure (p) exerted on the surfaces of a body can be expressed by linearizing Bernoulli's equation as follows:

$p=-\rho\left(\frac{\partial \phi}{\partial t}\right)_{x=-a}=i \omega \rho\left(\phi_{1}-\phi_{2}\right)_{x=-a} \quad \mathrm{x}=-\mathrm{a}$

$p=-\rho\left(\frac{\partial \phi}{\partial t}\right)_{x=a}=i \omega \rho\left(\phi_{2}-\phi_{3}\right)_{x=a} \quad \mathrm{x}=\mathrm{a}$

$p=\frac{-\rho g H_{i}}{2} \frac{\cosh k(z+h)}{\cosh k h}\left(1+k_{r}-k_{t}\right)$

Then, the hydrodynamic forces $\left(\mathrm{F}^{*}\right)$ exerted on the breakwater can be evaluated by integrating the pressure around the body's wetted surface as follows:

$$
\begin{aligned}
& F^{*}=\int_{-d}^{0} p(0, z) d z \\
& F^{*}=-\frac{\rho g H_{i}}{2 k}\left(1+k_{r}-k_{t}\right) \tanh k h \\
& F=\operatorname{Re}\left[F^{*} e^{-i \omega t}\right]
\end{aligned}
$$

\section{breakwater}

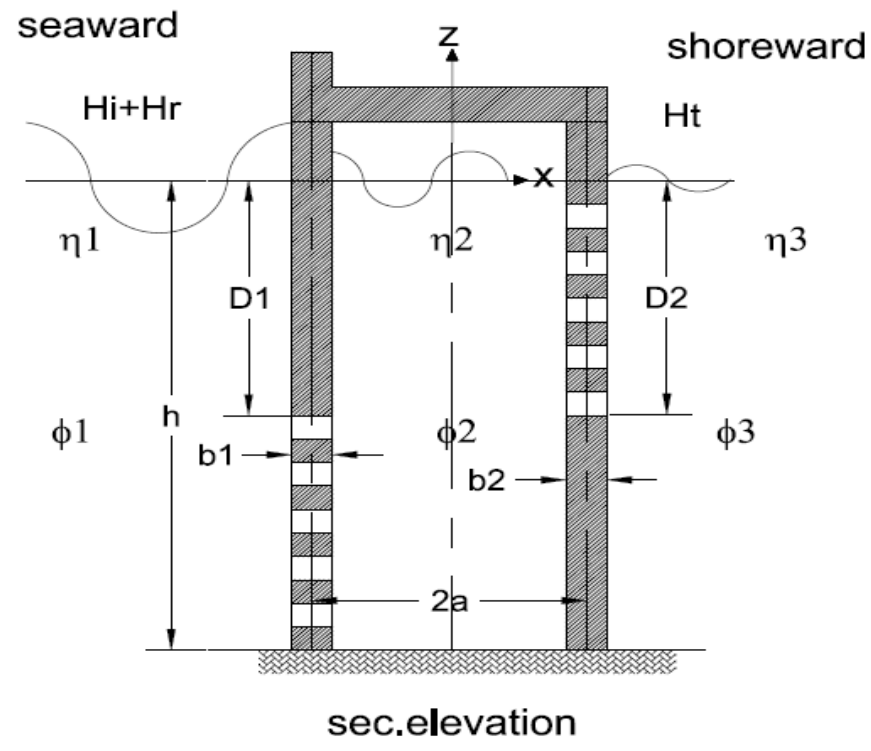

Figure (1) Definition sketch for a vertical perforated wall breakwater with horizontal slot

\section{breakwater}

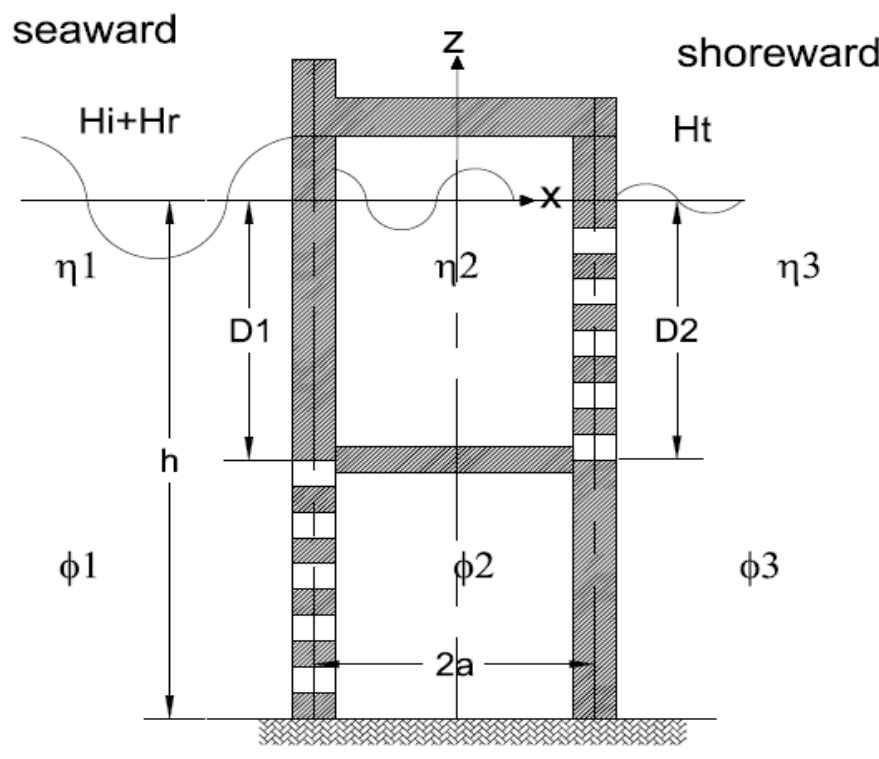

sec.elevation

Figure (2) Definition sketch for a vertical perforated wall breakwater without horizontal slot 


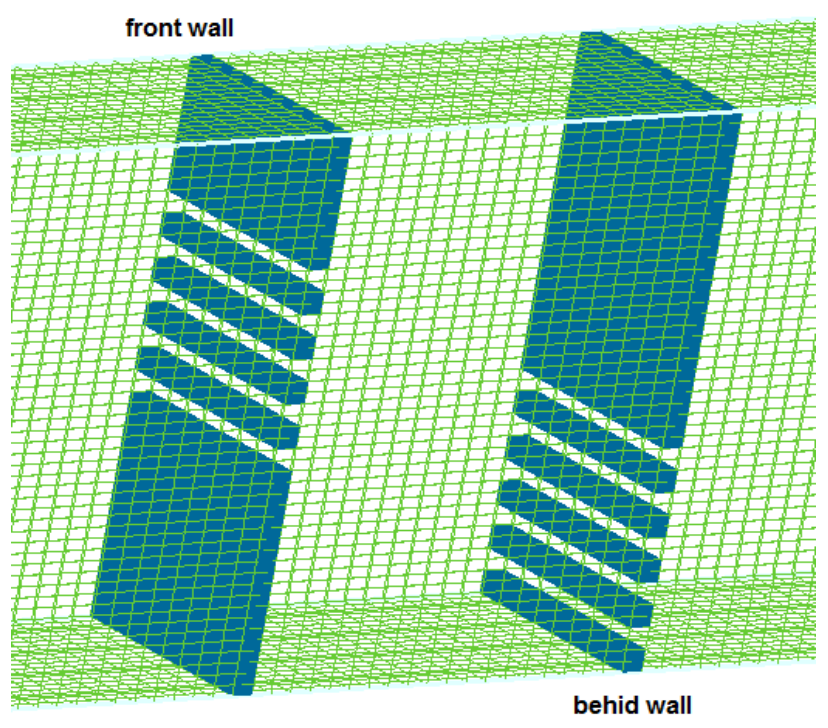

Figure (3) Breakwater model and Mesh blocks without horizontal slot

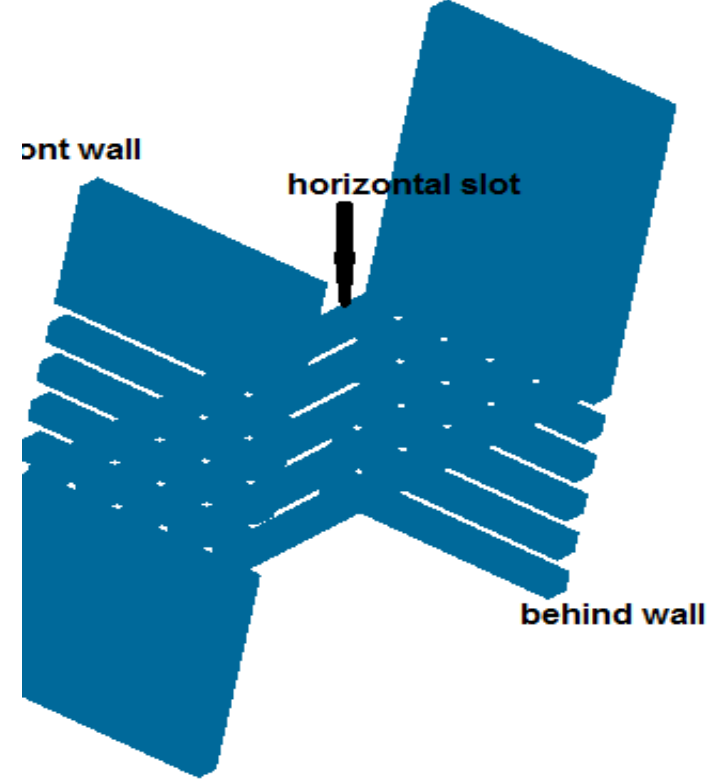

Figure (4) Breakwater model with horizontal slot

\section{RESULTS AND DESICCATIONS}

In this paper, the hydrodynamic performance of a new type breakwaters is studied using numerical models. The breakwater consists of a double vertical perforated walls (with and without horizontal slots). The first wall is impermeable in upper part and permeable in lower part. The second wall is permeable in upper part and impermeable in lower part. The transmission, the reflection, and the wave energy dissipation coefficients are presented for different waves and structure parameters. It Table (1) represents the results obtained from the experiments that was carried out in the Irrigation and Drainage Engineering laboratory of the Faculty of Engineering, Zagazig University. The experimental work was carried out without proposed breakwater to determine incident wave height and wave periods.
Table (1) the wave periods, lengths and incident wave heights for different wave generator frequencies without models

\begin{tabular}{|c|c|c|c|c|c|c|c|c|}
\hline Parameters & units & \multicolumn{7}{|c|}{ Ranges } \\
\hline $\begin{array}{c}\text { Incident } \\
\text { wave(Hi) }\end{array}$ & $\mathrm{Cm}$ & 6.7 & 7.6 & 8.2 & 9 & 10.1 & 11.5 & 12.5 \\
\hline $\begin{array}{c}\text { Wave } \\
\text { period (T) }\end{array}$ & Sec. & 1.4 & 1.35 & 1.3 & 1.2 & 1.1 & 1 & 0.9 \\
\hline $\begin{array}{c}\text { Water } \\
\text { depth(h) }\end{array}$ & $\mathrm{M}$ & 0.4 & 0.4 & 0.4 & 0.4 & 0.4 & 0.4 & 0.4 \\
\hline $\begin{array}{c}\text { Wave } \\
\text { ength(L) }\end{array}$ & $\mathrm{M}$ & 2.42 & 2.30 & 2.17 & 1.93 & 1.68 & 1.44 & 1.21 \\
\hline h/L & D.L & 0.17 & 0.17 & 0.18 & 0.21 & 0.24 & 0.28 & 0.33 \\
\hline $\begin{array}{c}\text { Chamber } \\
\text { width (2a) }\end{array}$ & $0.5 \mathrm{~h}$ & 0.2 & 0.2 & 0.2 & 0.2 & 0.2 & 0.2 & 0.2 \\
\hline
\end{tabular}

\subsection{THE WAVE FLUME}

The wave flume used in this work has a rectangular cross section with $2 \mathrm{~m}$ bed width and $1.2 \mathrm{~m}$ depth. The overall length of the flume is $12 \mathrm{~m}$. All sides of the flume are made of reinforced concrete of $0.25 \mathrm{~m}$ thickness. This flume is divided into three parts (i.e the inlet, working section and the outlet parts). A gravel wave absorber with slope 3:1 is installed at outlet part of the flume to absorb the transmitted waves. A general view of the flume is photo (1).

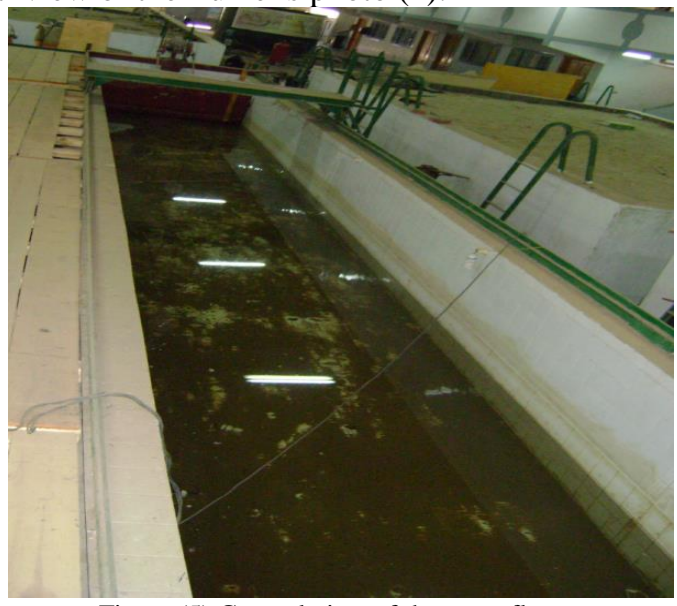

Figure (5) General view of the wave flume.

\section{2- ANALYSING THE RESULTS}

Figure (6) shows the wave high resulted from the experimental test conducted on the laboratory without using breakwater at different frequencies. Figuer (7) clear shows that the transion coefficant (kt) . Decresses with the increase of the relative depth $(\mathrm{h} / \mathrm{L})$ and with the comparasion of the first model and the second model it is cleared that the energy dispation coefficant is better for the first model than the second in the range betwwen $10-15 \%$. Fig(8) Comparison of predicted(double perforated walls without horizontal slot) hydrodynamic coefficients ( $\mathrm{kt}, \mathrm{kr}$ and $\mathrm{kl}$ ) with results from $\mathrm{Ji}$ and Suh (2010) as a function of $\mathrm{d} / \mathrm{L}$, when $\mathrm{D} / \mathrm{d}=0.5, \mathrm{~B} / \mathrm{d}=1, \varepsilon$ $=0.5, f=2$. Fig. (9). Comparison of predicted hydrodynamic coefficients (kt, kr and kl) with results from Laju et al. (2011) as a function of $\mathrm{d} / \mathrm{L}$, when $\mathrm{D} / \mathrm{d}=0.35, \mathrm{~B} / \mathrm{d}=0.5, \varepsilon=0.25$ and $f$ $=1.2$ Fig. (10) Comparison of predicted and (Flolw-3D) hydrodynamic coefficients ( $\mathrm{kt}$ and $\mathrm{kr}$ ) with results from Laju et al. (2011) as a function of $\mathrm{d} / \mathrm{L}$, when $\mathrm{D} / \mathrm{d}=0.35, \mathrm{~B} / \mathrm{d}=0.5, \varepsilon=$ 0.25 and $f=1.2$

From figure (11) the effect of the wave force on the first model is bigger than its effect on the second model. It also can be seen 
that with the increase of the relative depth the variation between the two models is increased.

Fig

(12) shows the model in CED (FLOW-3D) and the location of measuring probes. Fig (13) shows the free surface elevation (cm)after 2.0 meters from breakwater by using (FLOW -3D) at wave period $(\mathrm{T})=0.9 \mathrm{sec}$ and $1.1 \mathrm{sec}$. Fig (14) shows surface elevation $(\mathrm{cm})$ at wave period $\mathrm{T}=1.5 \mathrm{sec}$, wave translated at probe (1)and wave reflected at probe (2).

The numerical model results are used to detect the velocity field and the velocity vectors in the surrounding barrier.

Figure (15) shows the velocity vector and velocity field for one cycle of with time increment of $0.1 \mathrm{sec}$ of wave frequency $=1$ $\mathrm{Hz}$, calculated with FLOW-3D

The higher velocities are observed at the crest of wave and around the slots.

The higher velocities are formed trough of slots as a result to effect of obstacle

The velocity magnitude is very high in front of the barrier and very low behind it

The flow in the area between the barriers is turbulence and the motion seems a vertically except the region that located near the slots.

The set of the experimental results used in order to examine the effect of the shape and chamber width in mean velocity fields at constant porosity $=50 \%$ and $\mathrm{D} / \mathrm{h}=0.5$ includes 2 tests. The first Test is a double perforated walls with horizontal slots for $\mathrm{B} / \mathrm{h}=0.5$ and $\mathrm{B} / \mathrm{h}=1.0$ the mean velocity field in the breakwater area is presented in figure (16) (a)- $\mathrm{t}=10.25 \mathrm{~T}$, (b)$\mathrm{t}=10.50 \mathrm{~T}$ and $(\mathrm{c})-\mathrm{t}=10.75 \mathrm{~T}$ over the $10^{\mathrm{th}}$ wave cycle. Maximum velocities $72.9 \mathrm{~cm} / \mathrm{s}$ are observed in the region of the impermeable barriers (figure 16) and mainly in the seaward side of the structures where the main structure-interaction takes place and intense vortices are observed. A recirculating region is observed in the region beneath the body of each barrier with the first one being stronger and wider the mean velocity field for permeable barriers with porosity 0.50 is presented. observed in the impermeable barriers case under the same hydrodynamic conditions. The recirculating region this time is obvious only beneath the first barrier while the interaction of the water mass with the gaps on the body of the barriers is presented. In figure (17) Maximum velocities $56.7 \mathrm{~cm} / \mathrm{s}$ observed velocity for $\mathrm{B} / \mathrm{h}=1.0$ bigger than velocity for $\mathrm{B} / \mathrm{h}=0.5$ at the same condition.

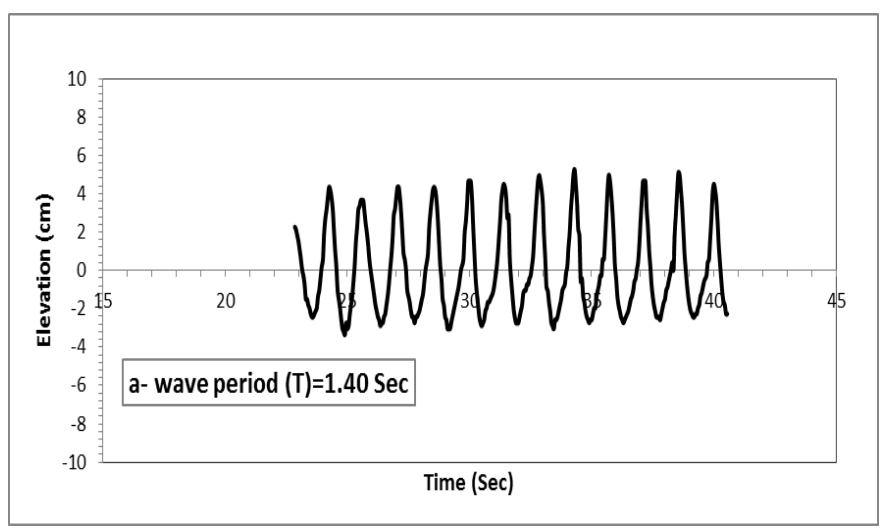

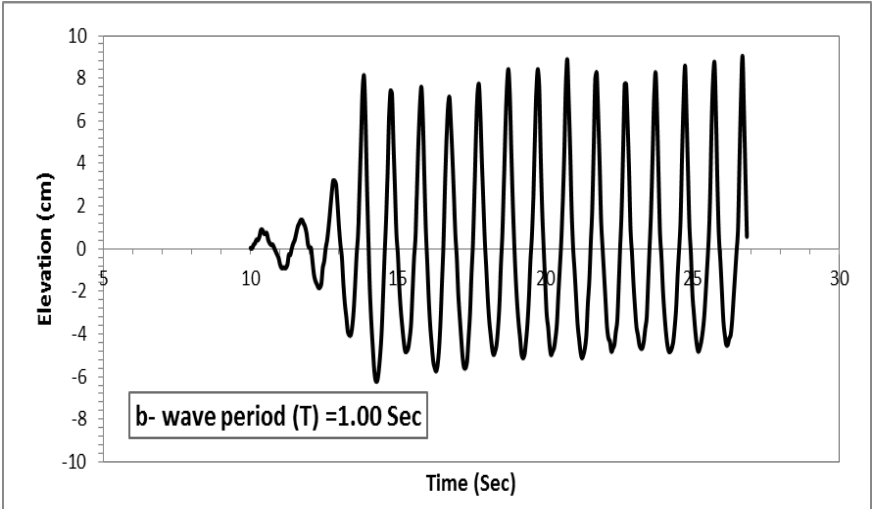

Figure (6) Waves profiles for wave periods: (a) $\mathrm{T}=1.40$, (b) $\mathrm{T}=1.00 \mathrm{sec}$

(a) Transimisson C oefficient
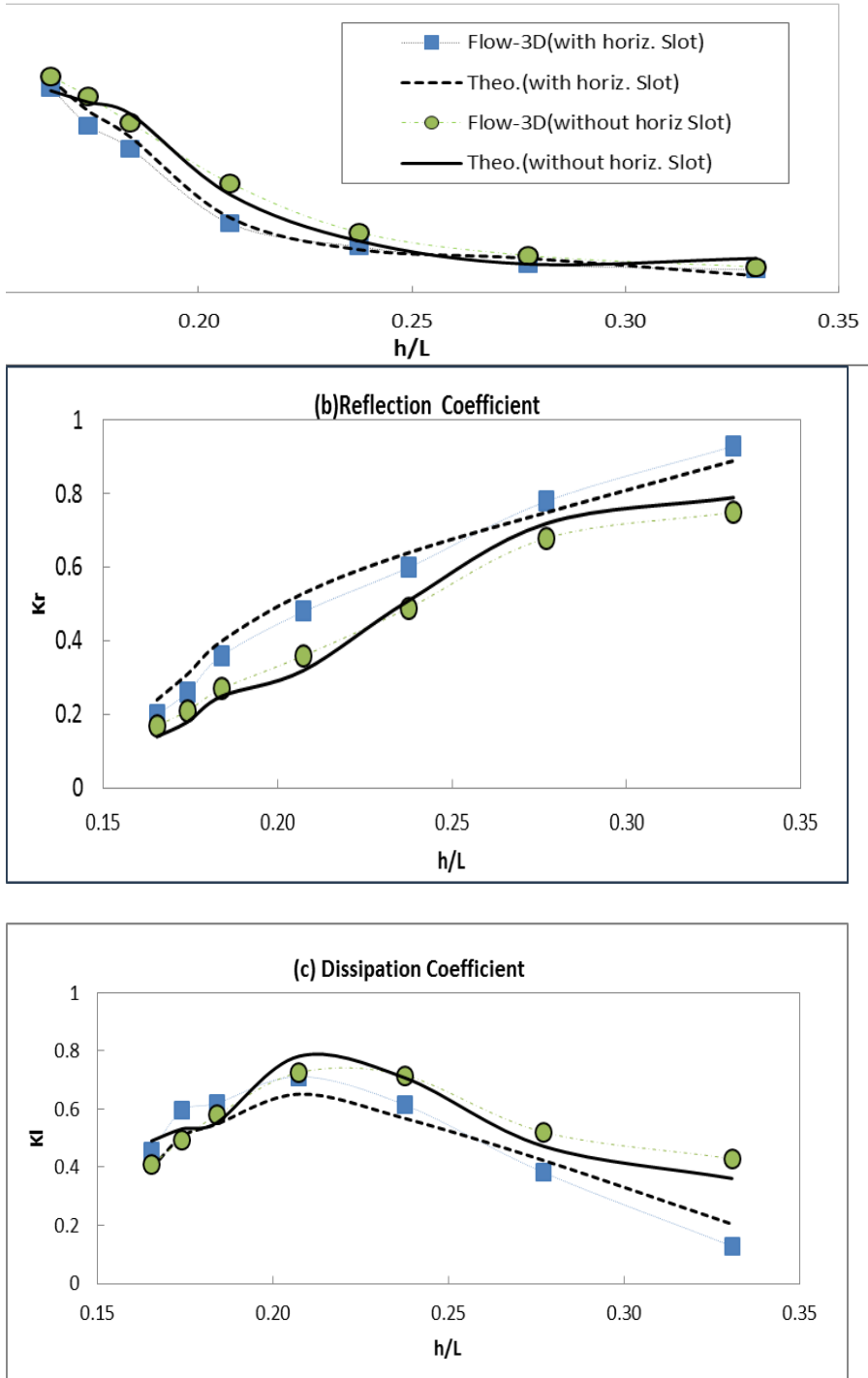

Figure (7) Comparison between CFD (FLOW-3D) and predicted results for a double perforated walls with horizontal wall slot and without horizontal wall slot as function of $(\mathrm{h} / \mathrm{L})$ at $2 \mathrm{a}=0.5 \mathrm{~h}, \% 05=\varepsilon$ (a) $\mathrm{kt}$, (b) $\mathrm{kr}$ and (c) 

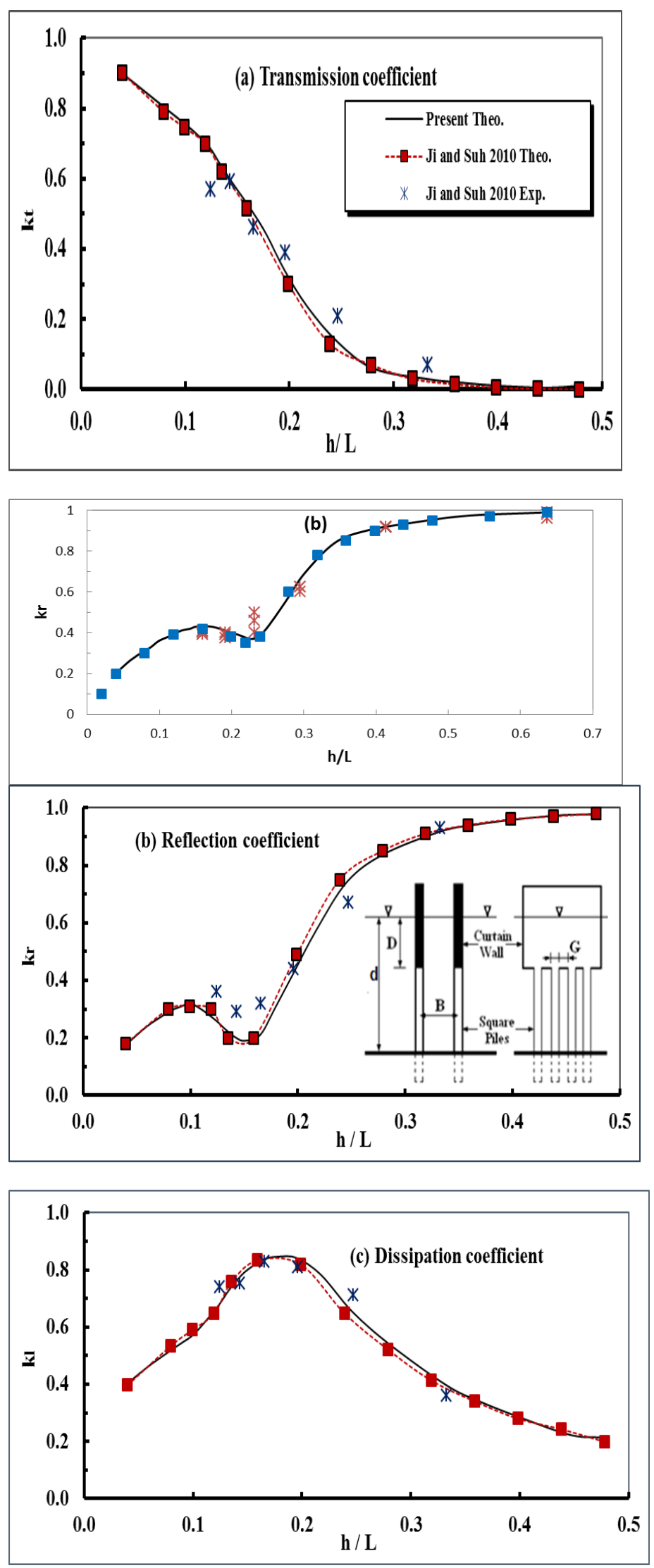

Figure (8) Comparison of predicted (double perforated walls without horizontal slot) hydrodynamic coefficients (kt, $\mathrm{kr}$ and $\mathrm{kl}$ ) with results from $\mathrm{Ji}$ and Suh (2010) as a function of h/L, when $\mathrm{D} / \mathrm{d}=0.5, \mathrm{~B} / \mathrm{d}=1, \varepsilon=0.5, f=2$
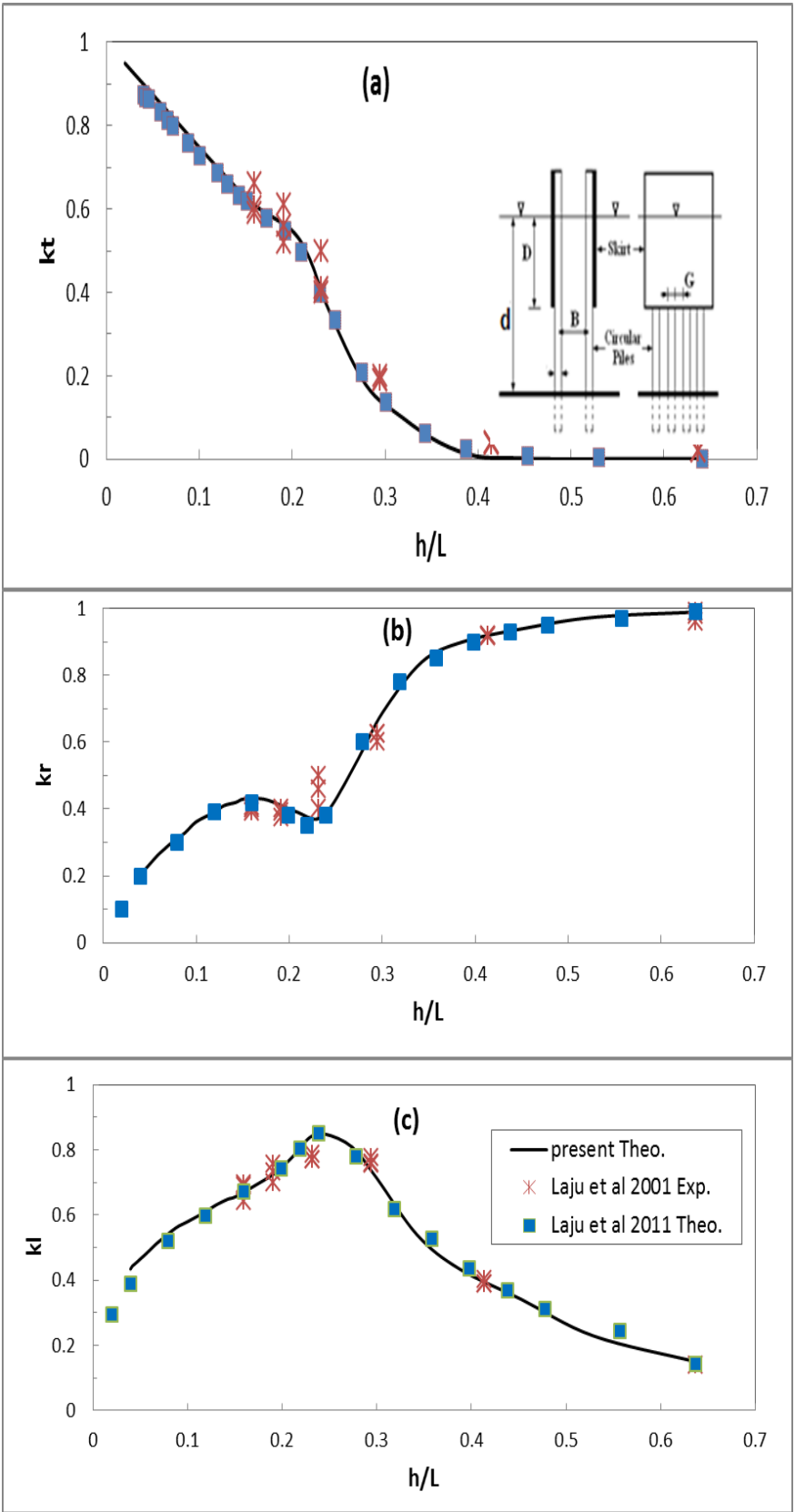

Fig.(9) Comparison of predicted (double perforated walls without horizontal slot) hydrodynamic coefficients (a)kt, (b)kr and (c)kl with results from Laju et al. (2011) as a function of $\mathrm{h} / \mathrm{L}$, when $\mathrm{D} / \mathrm{d}=0.35, \mathrm{~B} / \mathrm{d}=0.5, \varepsilon=0.25$ and $f=1.2$ 

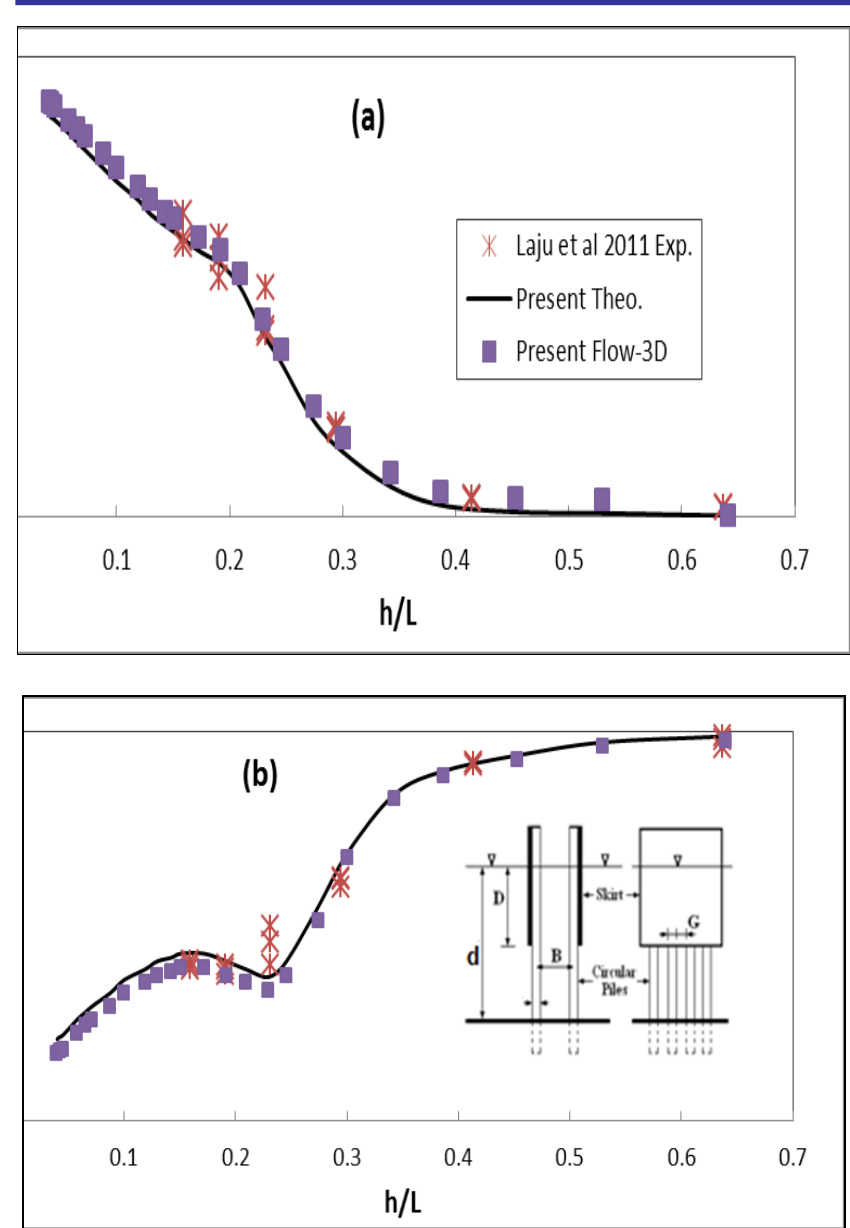

Fig.(10) Comparison of predicted and (Flolw-3D) (double perforated walls without horizontal slot) hydrodynamic coefficients (a)kt and(b) kr with results from Laju et al. (2011) as a function of $\mathrm{d} / \mathrm{L}$, when $\mathrm{D} / \mathrm{d}=0.35, \mathrm{~B} / \mathrm{d}=$

$$
0.5, \varepsilon=0.25 \text { and } f=1.2
$$

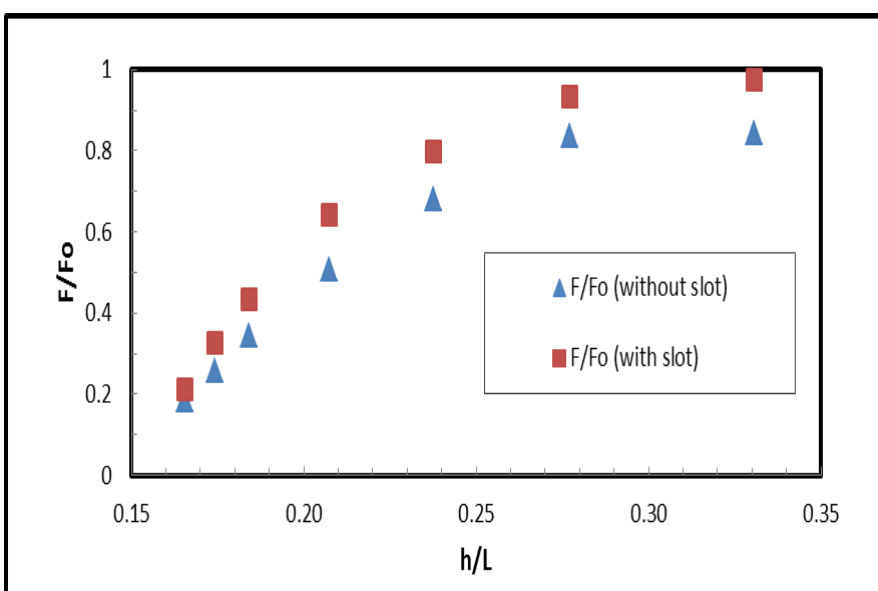

Fig.(11) Comparison of dimensionless wave forces between a double perforated walls with horizontal slot and a double perforated walls without horizontal slot as function of $(d / L \varepsilon=0.5$

\section{) for 2 圆 $=0.5 d$ and}

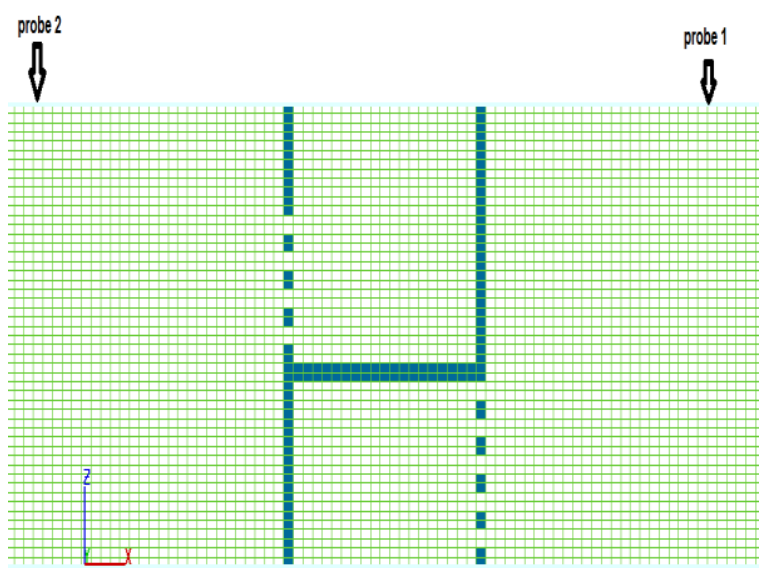

Fig. (12) wave direction, location wave reflection and wave translation

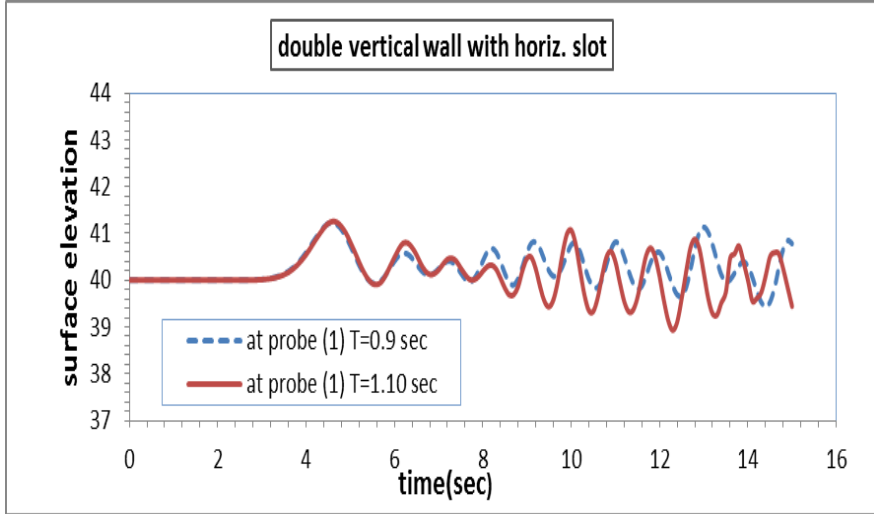

Fig (13) Free surface elevation (cm) after 2.00 meters from breakwater by using (FLOW -3D).

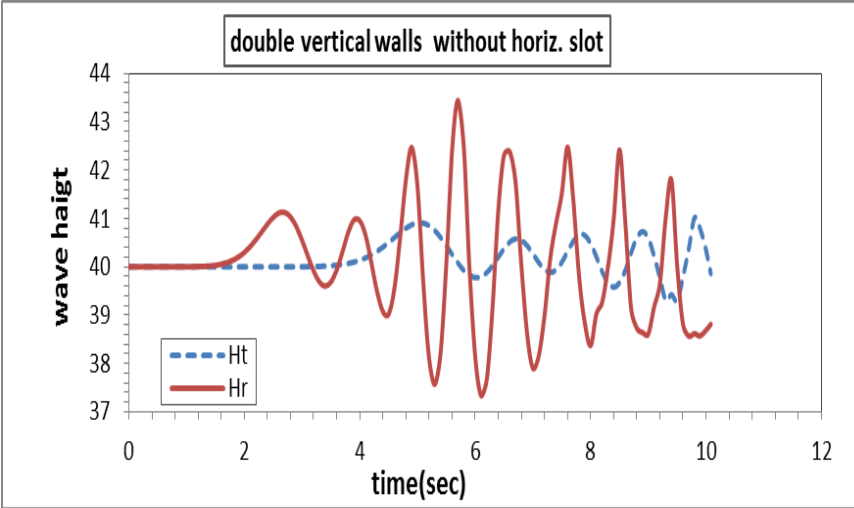

Fig (14) surface elevation $(\mathrm{cm})$ at wave period $\mathrm{T}=1.5 \mathrm{sec}$, wave translated at probe 1 and wave reflected at probe 2

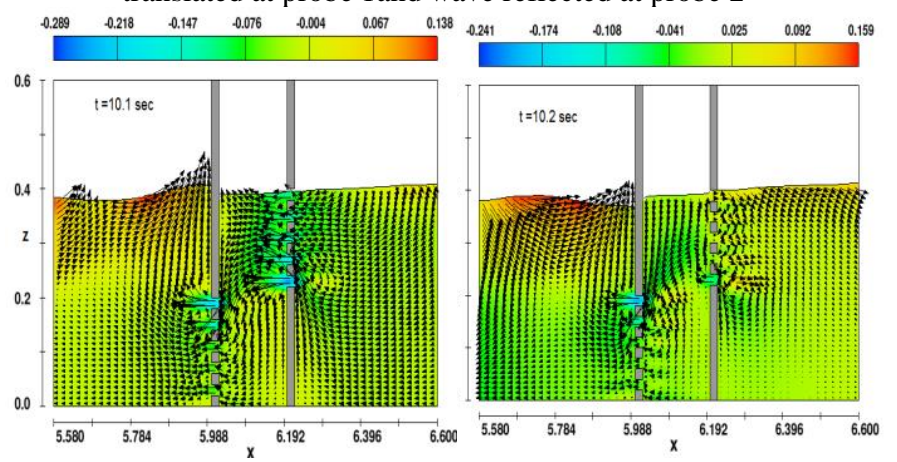



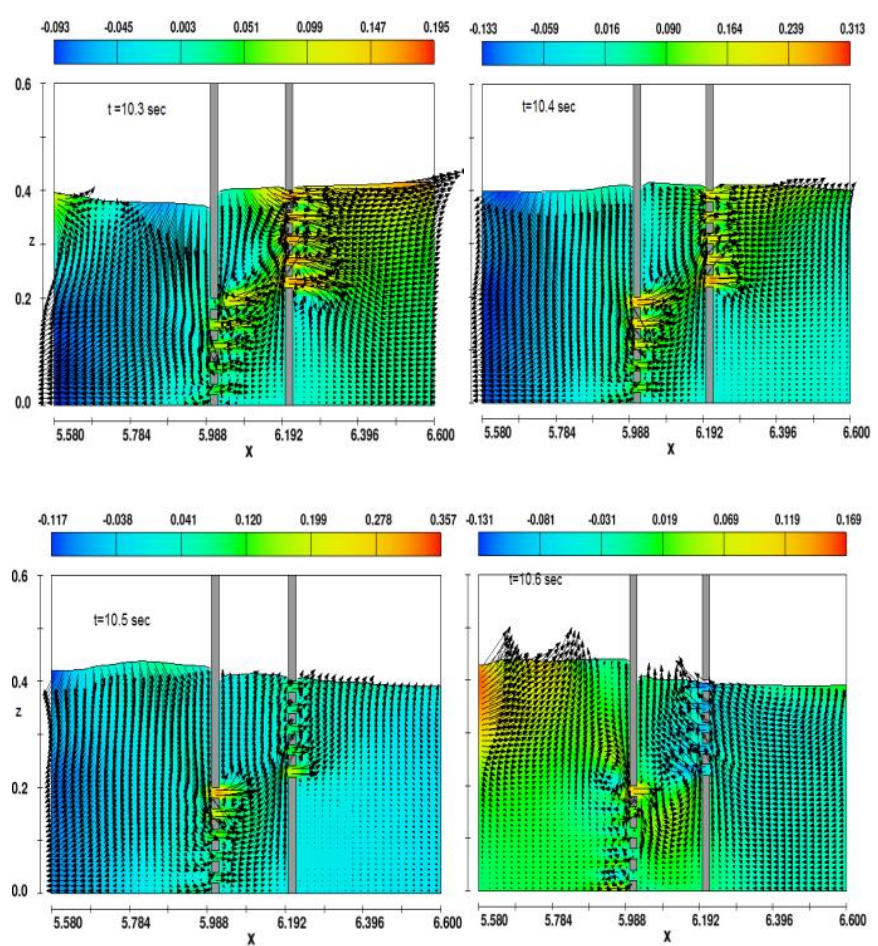

Z

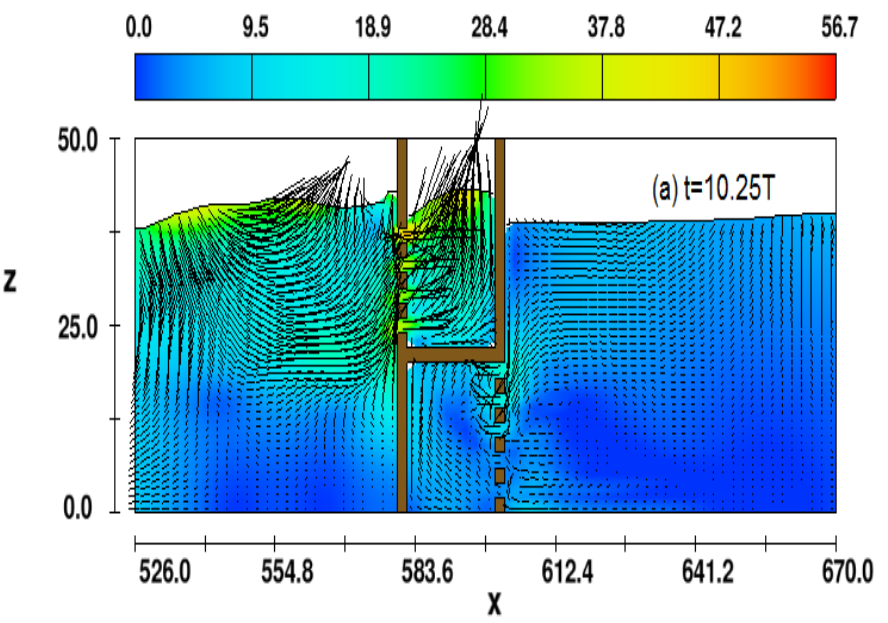

velocity magnitude and vectors

$(\underline{\max }=5.58 \mathrm{E}+01)$
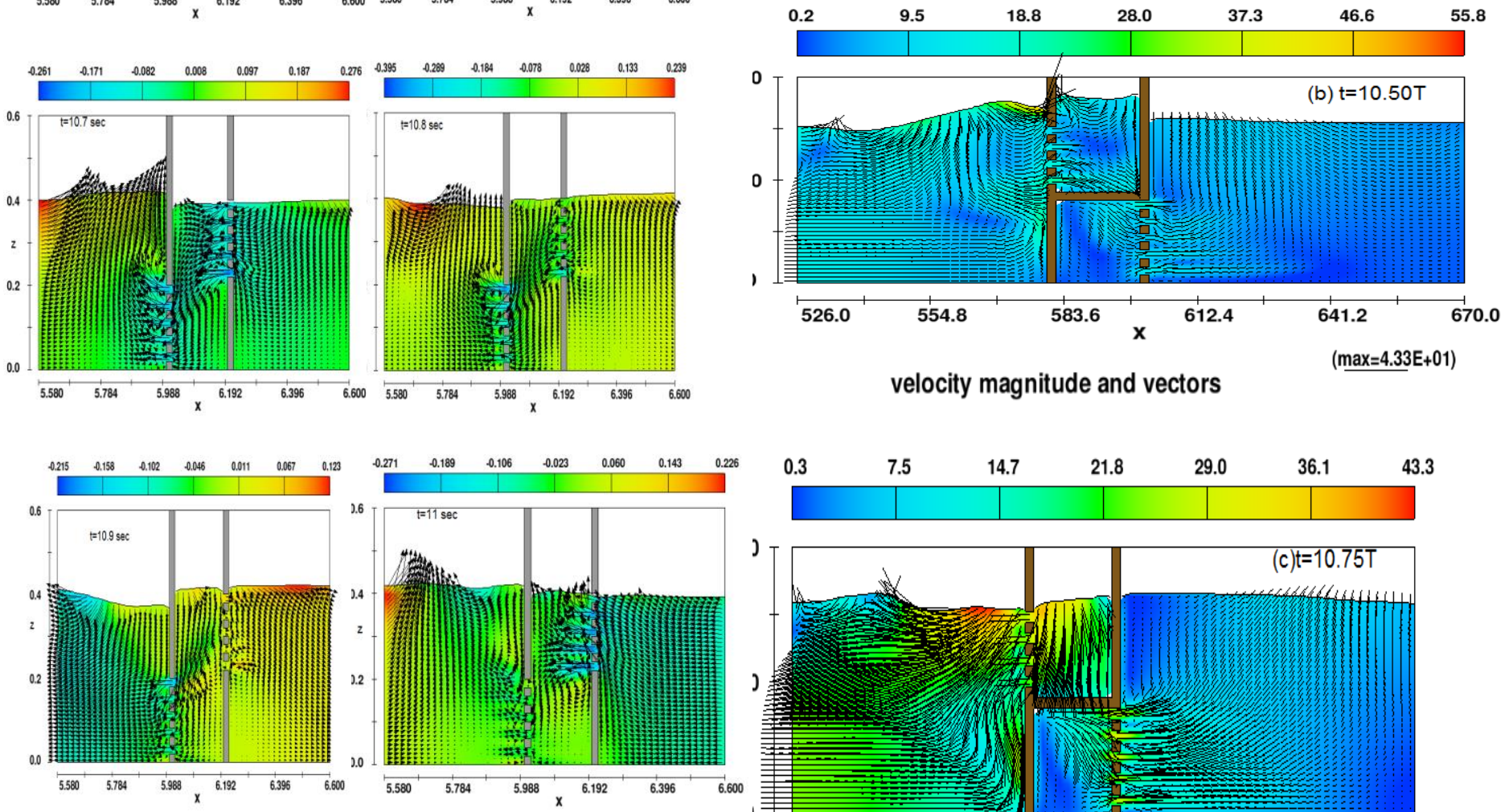

Figure (15) Velocity magnitude $(\mathrm{cm} / \mathrm{s})$ and velocity vector of FLOW-3D results for $\mathrm{T}=1.2 \mathrm{sec}, \mathrm{Hi}=9 \mathrm{~cm}, d t=0.1 \mathrm{sec} 2 \mathrm{a} / h=0.5$

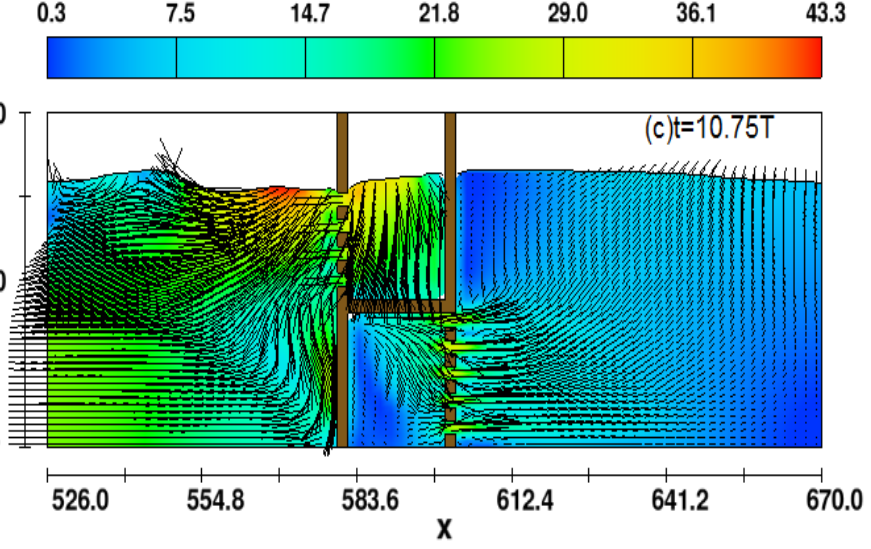

Figure (16) Detailed velocity field in the region of the barriers (Porosity $=0.50, \mathrm{~B} / \mathrm{h}=0.5$ and $\mathrm{Hi}=9 \mathrm{~cm}-\mathrm{T}=1.20 \mathrm{sec}$ ). 
velocity magnitude and vectors

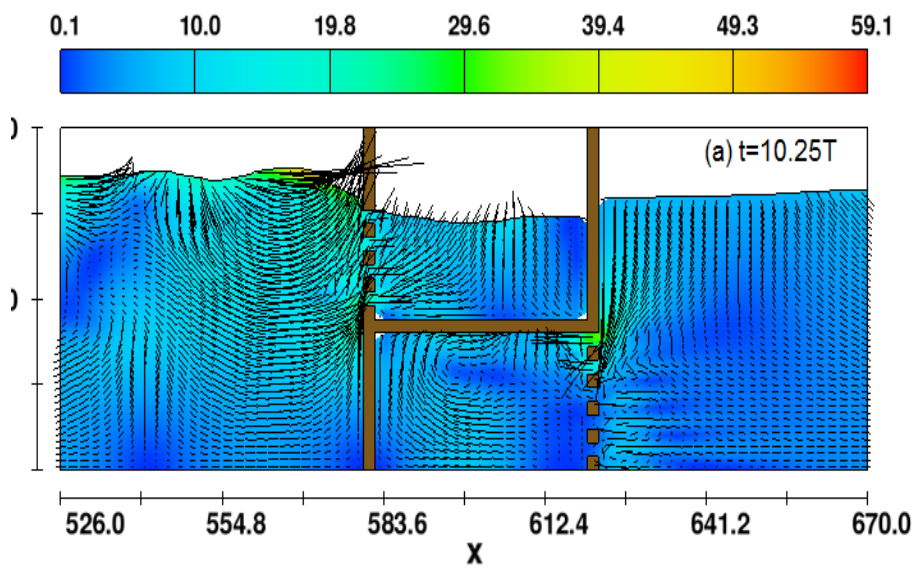

velocity magnitude and vectors

$z$
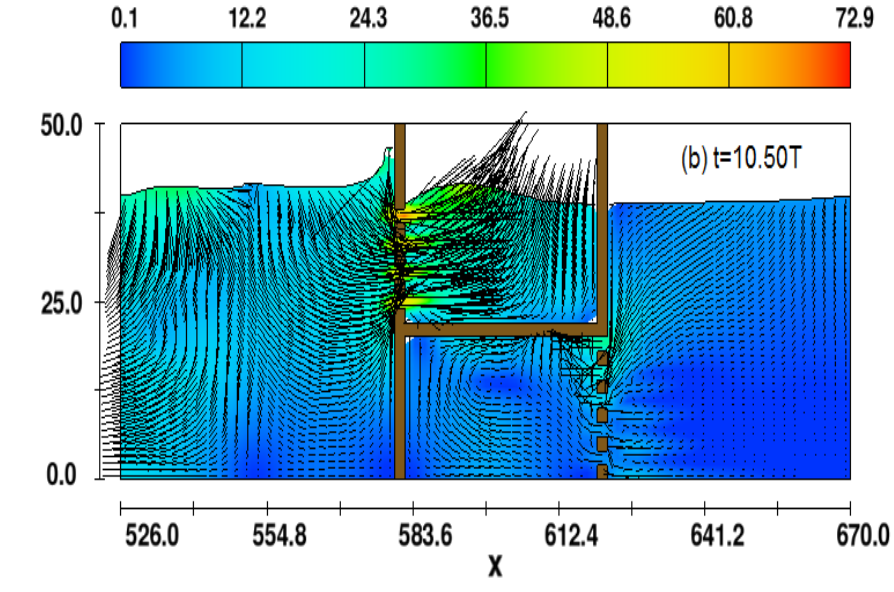

velocity magnitude and vectors

$(\max =7.63 \mathrm{E}+01)$

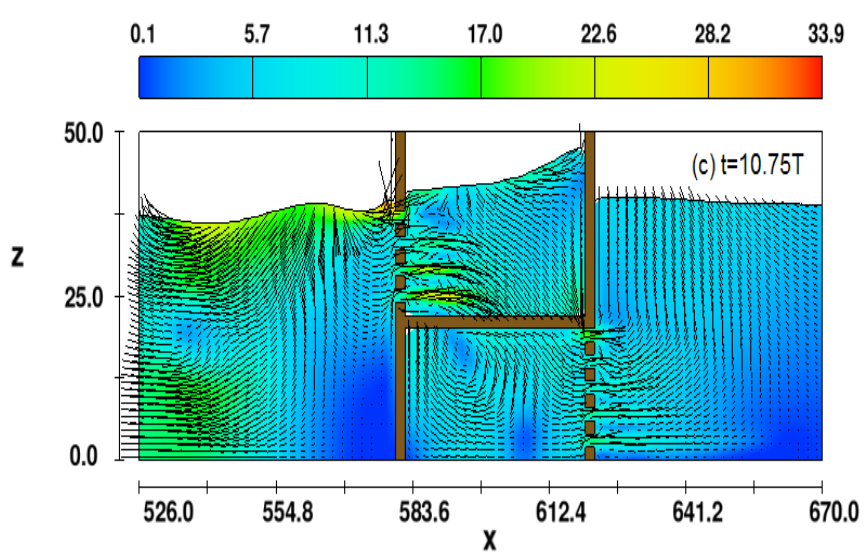

Figure (17) Detailed velocity field in the region of the barriers (Porosity $=0.50, \mathrm{~B} / \mathrm{h}=1.0$ and $\mathrm{Hi}=9 \mathrm{~cm}-\mathrm{T}=1.20 \mathrm{sec}$ ).

\section{5- CONCLUSIONS}

- The reviewed literature revealed that the breakwaters were physically modeled and investigated meticulously but breakwater numerical modeling has some discrepancies. It was also clear that extra investigations are needed. Among the reviewed available models, model Flow 3-D was found to be capable of simulating the proposed breakwater.

- Flow-3D was validated against extensive laboratory investigations and theoretical model.

- Flow -3D is capable of describing the wave interaction of a linear wave with double vertical perforated walls. Flow -3D is capable of reproducing most of the important features of the experimental data and semi-analytical results. Flow -3D reproduced numerical results that are perfectly acceptable.

- The wave force on the proposed models increases with increasing the relative length $(\mathrm{h} / \mathrm{L})$.

- The effect of wave force on the first model is bigger than the second model in the range (10-15\%).

- The transmission coefficient (kt) decreases with increasing the relative length $(\mathrm{h} / \mathrm{L})$. and the reflection coefficient $(\mathrm{kr})$ increases with increasing the relative length $(\mathrm{h} / \mathrm{L})$.

- The comparasion of the first and the second model it is cleared that the energy dispation coefficant is better for the first model than that for the seconde in the range betwwen $10-15 \%$.

- The hydrodynamic performance of the seconed model is lower than that of the previous study in the rang of $(3-7 \%)$.

- FLOW-3D results are able to find values velocity in front of and behind barriers.

- Velocity magnitude for $\mathrm{B} / \mathrm{h}=1.0$ bigger than velocity for $\mathrm{B} / \mathrm{h}=0.5$ at the same condition.

\section{NOTATIONS}

The following symbols have been adopted for use in this paper:

- $\mathrm{A}_{10}=$ complex reflection coefficient;

- $\mathrm{A}_{40}=$ complex transmission coefficient;

- $\mathrm{A}_{1 \mathrm{n}} \quad=$ complex unknown coefficients;

- $\lambda=$ half distance between the two walls;

- $\mathrm{b} \quad=$ thickness of the vertical wall;

- $\mathrm{C}_{\mathrm{m}} \quad$ =added mass coefficient;

- $f \quad=$ friction coefficient;

$\mathrm{G} \quad=$ permeability parameter;

- $\mathrm{g}=$ acceleration of gravity;

- $\mathrm{h}_{\mathrm{i}} \quad$ = incident wave height;

- $\mathrm{h}_{\mathrm{r}} \quad$ = reflected wave height;

- $\mathrm{H}_{\mathrm{t}}=$ transmitted wave height;

- $\mathrm{h} \quad=$ water depth;

- $\mathrm{k} \quad=$ incident wave number;

- $\mathrm{k}_{\mathrm{l}} \quad$ = energy dissipation coefficient;

- $\mathrm{k}_{\mathrm{r}} \quad$ = reflection coefficient;

- $\mathrm{k}_{\mathrm{t}} \quad=$ transmission coefficient;

- $\mathrm{L} \quad=$ wave length;

- $\mathrm{T}=$ wave period;

- $\mathrm{t}=$ time; 
- $\quad \mathbf{x}, \mathbf{z}=$ two dimensional axis;

- $\varepsilon_{1}=$ porosity of the lower part of the first wall;

- $\phi_{\mathrm{p}}=$ total flow velocity potential;

- $\phi_{1}=$ seaward velocity potential;

- $\phi_{2}=$ velocity potential between the two walls;

- $\phi_{3}=$ shoreward velocity potential;

$\omega=$ angular wave frequency.

- $\mathrm{F}^{*} \quad=$ wave force

\section{REFERENCES}

[1] Ahmed, H., 2011. "Wave Interaction with Vertical Perforated wallsas a Permeable Breakwater," PhD. Thesis, Hydro Sciences (IGAW), Bergische University of Wuppertal, Germany, 2011.

[2] Hayashi, T., \& Kano, T., 1966. "Hydraulic research on the closely space Pile breakwater." $10^{\text {th }}$ Coastal Eng. Conf., ASCE, New York, Vol. 11, Chapter 50.

[3] Herbich, J. B., 1989. "Wave transmission through a double-row Pile breakwater." Proc. 21 st Int. Conf. on Coastal Eng., ASCE, Chapter 165, Torremolinos, Spain

[4] Hirt, C. W. and Nichols, B. D., 1981. "Volume of Fluid (VOF) method for the dynamics of free boundaries," J. Computat. Phys., vol. 39, no. 1, pp. 201-225.

[5] Hsu, H-H. \& Wu, Y-C., 1999. "Numerical solution for the secondorder wave interaction with porous structures." International Journal for Numerical Methods in Fluids, Vol. 29 Issue 3, pp. $265-$ 288.

[6] Huang, C. J.; Chang, H. H.; and Hwung, H. H., 2003. "Structural permeability effects on the interaction of a solitary wave and a submerged breakwater," Coastal Engineering. Vol. 49, pp. 1-24.

[7] Isaacson, M.; Baldwin, J.; Premasiri, S. and Yang, G., 1999. "Wave interaction with double Perforatedbarrier,"Applied ocean research, Vol. 21, pp. 81-91.

[8] Isaacson, M.; Premasiri, S. and Yang, G., 1998. "Wave interaction with vertical Perforatedbarrier," J. of Waterway, Port, Coastal and Ocean Engineering, vol. 124, no. 3, pp. 118-125.

[9] Karim, M. F.; Tanimoto, K. and Hieu, P. D., 2009 "Modelling and simulation of wave transformation in porous structures using VOF based two-phase flow model," Applied Mathematical Modellin. vo 33 , pp. 343-360.
[10] Koraim, A. S.; Heikal; E. M. and Rageh,O. S., 2011 "Hydrodynamic characteristics of double permeable reakwater undregular waves," Coastal Eng., vol. 24, pp. pp.503-527.

[11] Koraim, A. S; Iskander, M. M. and Elsayed, W. R., 2014 "Hydrodynamic performance odouble rows of piles suspending horizontal c shaped bars," Coastal Eng., vol. 84, pp. 81-96.

[12] Laju, K., Sundar, V. \& Sundaravadivelu, R., 2007. "Studies on Pile supported double skirt breakwater models." Journal of Ocean Technology, Vol. 2, No.1. pp. 32-53.

[13] Lara, J.; Garcia, LN. and Losada, I.J., 2006. "RANS modelling applied to random wave interaction with submerged permeable structures," Coastal Engineering, vol. 53, pp. 395-417.

[14] Lara, J.L.; Losada, I.J. and .Guanche, R., 2008. "Wave interaction with low-mound breakwaters using a RANS model," Ocean Engineering, vol. 35, pp. 1388- 1400.

[15] Lin, P.; and Karunarathna, .S.A., 2007. "Numerical stud of solitary wave interaction with porous breakwaters," J. of waterway, port, coastal and ocean engineering. , pp. 352-363.

[16] Mansard, E .P. D. \& Funke, E. R., 1980. "The measurement of incident and reflected spectra using a least squares method." In Proc. 17th Coastal Eng. Conf., Sydney, Australia, pp 159-174.

[17] Rageh, O.S.; Koraim, A.S., 2010. "Hydraulic performance of vertical walls with horizontal sloed as breakwater," Coastal Engineering, vol. 57, pp. 745-756, 2010.

[18] Sollit, C. K. \& Cross, R.H., 1972. "Wave transmission through permeable breakwaters." Proceedings of the 13th Coastal Eng. Conf., ASCE, Vancouver, pp. 1827-1846.

[19] Suh, K. D., Shin, S. \& Cox, D. T., 2006. "Hydrodynamic characteristics of Pile-Supported vertical wall breakwaters." J. of Waterways, Port, Coastal and Ocean Engineering, Vol.132, No.2, pp.83-96.

[20] Suh, K.D., Park, W.S., 1995. Wave reflection from perforated-wall caisson breakwaters. Coastal Engineering 26, 177-193.Suh, K-D., Park, J.K., Park, W.S., 2006. Wave reflection from partially perforated-wall caisson breakwater. Coastal Engineering 33, 264 280 .

[21] Wiegel, R. L., 1960. "Transmission of wave past a rigid vertical thin barrier" J. Waterway, Port, Coastal and Ocean Eng., ASCE, Vol. 86, No.1

[22] Yu, X., 1995. "Diffraction of water waves by porous breakwater.", J. of Waterway, Port, Coastal and Ocean Engineering, Vol. 121, No. 6, pp. 275-282. 